\title{
Insurance applications of dependence modeling
}

\author{
An interview with Edward (Jed) Frees
}

https://doi.org/10.1515/demo-2020-0005

Received March 18, 2020; accepted March 20, 2020

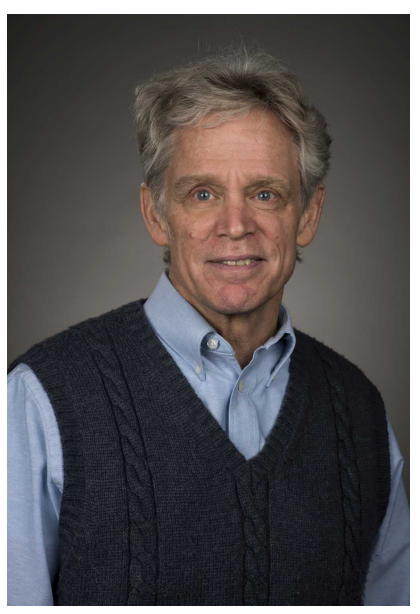

Edward (Jed) Frees is an emeritus professor with the University of WisconsinMadison. He served there from 1983 to 2018, where his most recent appointment was as the Hickman Larson Chair of Actuarial Science. In addition, he currently has a fractional appointment with the Australian National University. He received his $\mathrm{PhD}$ in mathematical statistics from the University of North Carolina at Chapel Hill in 1983 and is the only Fellow of both the Society of Actuaries (SoA, 1986) and the American Statistical Association (1997). He has provided extensive service to the profession, including serving as the founding chairperson of the SoA Education and Research Section (1991-92), a member of the SoA Board of Directors (2005-08), a Trustee of the Actuarial Foundation (1998-2001), the Editor of the North American Actuarial Journal (2000-04), and as an actuarial representative to the Social Security Advisory Board's Technical Panel on Methods and Assumptions (1998-2000). He has written three books (1996, 2004, 2010), edited a two-volume series on Predictive Modeling Applications in Actuarial Science, and is editing an online, open source book titled "Loss Data Analytics." He has published extensively and won several awards for his research. He twice received the SoA's Annual Prize for best paper published by the Society $(1991,2018)$, the SoA's 1997 Edward A. Lew Award for research in modeling, the Casualty Actuarial Society's 2010 Hachemeister Prize and 2015 ARIA Prize, and the Halmstad Prize for best paper published in the actuarial literature (1992, 1998, 1999, 2011).

Within the actuarial profession, Jed Frees is widely regarded as a researcher who attracted the community's attention to copula modeling as a flexible and efficient way of accounting for dependence and measuring its effects in insurance contexts. His 1998 review paper [21] with Emiliano Valdez, published in the North American Actuarial Journal, was an eye opener for the profession and stimulated a great deal of research, including from his own team. Through three books and nearly 100 journal articles, refereed book chapters, technical reports, and dictionary entries, Jed contributed not only to insurance claim modeling, loss reserving, and credibility theory but also to longitudinal and panel data analysis, sequential analysis, and nonparametric statistics. This interview recaps his career and describes some of his views on research, education and service. In the following, our questions to Jed are bold-faced.

\footnotetext{
^Corresponding Author: Christian Genest: Department of Mathematics and Statistics, McGill University, Montréal (Québec) Canada, E-mail: christian.genest@mcgill.ca

Matthias Scherer: Lehrstuhl für Finanzmathematik, Technische Universität München, Garching, Germany
} 


\section{Background and early academic career}

\section{Let us start at the beginning. What was your childhood like?}

I grew up in southern Ohio, outside of Dayton, as the eldest of four boys. My parents met at Miami University in Ohio and so it was not surprising that later on I, and two of my brothers, also went there for an undergraduate education (the fourth went to a smaller school on an athletic scholarship, not part of the tradition). As a family we played an awful lot of cards together (in part due to my Mom who was an avid, and excellent, bridge player) and we like to think that this helped our math abilities. Also as a family, we owned a small restaurant in which I spent a lot of time during my formative years; presumably this provided me with some discipline that allowed me to be successful during my actuarial education.

\section{How did you decide to become an actuary and a statistician?}

I used a standard recipe for entering the actuarial profession. In college, I was a math major interested in applications. I had explored physics and computer sciences as major fields of study beforehand. Physics, although interesting, had too many gifted people that I would have to compete with and the introductory courses in computer science, in the early 1970s, consisted of a lot of binary arithmetic that I did not find challenging. So, for math majors interested in applications, choices focused on engineering and actuarial science. I chose the latter because it had more to do with people.

After receiving my undergraduate degree in math (from Miami University, 1975), I went to University of Wisconsin at Madison (UW) for a Master's degree in actuarial science. I had the great fortune to have for my thesis adviser James C. Hickman (1927-2006), who later became not only a mentor but also a colleague, boss, and a friend on my return to UW as a faculty member. Hickman was an inspiration to all who knew him; I documented his contributions in a 2007 paper [13].

Upon graduation in 1976, I worked as an entry level actuary for three years, splitting time at an actuarial consulting firm in Seattle, another in Wellington, New Zealand, and then at the Government Actuaries Department in London, England. For a portion of my time there, I worked under Steven Haberman, now a well-known actuarial scholar, who gave me additional exposure to actuarial research. I was one of $5000 \mathrm{UK}$ civil servants living in London in the late 1970's, good fun. My actuarial work used a lot of computing tools (Fortran and Cobol back then) and exposed me to different actuarial practice areas with a heavy emphasis on pensions. However, I also used a lot of data and came to realize that I had no formal data training and would not receive any through the actuarial education curriculum.

So, I entered a graduate statistics program at the University of North Carolina in Chapel Hill (UNC). I did not realize it at the time but this was a big step moving from industry back to academia. (Over the years, I have regularly tried to lure select talented former students from industry back to academia with little success. The good ones are doing too well in industry.) But for me, the transition was quite natural. Interestingly, I thought that I had applied for a Master's program at UNC but it turned out I was in the same cohort as the doctoral students; they had the same pipeline back then. So, I became a doctoral student in statistics and subsequently graduated based on a thesis [8] in sequential analysis under David Ruppert and Gordon Simons; I continued to collaborate with David for a while [19, 20].

\section{How did your early academic career evolve?}

Demography was in my favor and there were many good positions available upon my graduation and certainly not as much competition then as there is now. I was fortunate to land a job at my alma mater, UW, where I wound up staying for 35 years. I was initially joint between Statistics and the Business School, so my early work focused on mathematical statistics and applications in business. For applications, I initially worked with colleagues in finance, marketing, operations research, and accounting. For mathematical statistics, I stayed with my thesis area for only a couple of years.

I moved away from sequential analysis because almost all of the data we saw back then in business were observational, not under the control of analysts, and certainly not subject to sequential interventions. Fortunately, the study of sequential analysis had forced me to sharpen my mathematical tools. I learned a lot working in business but my math skills definitely became duller during the three-year hiatus from academia. 
With this and my business background, starting with the paper [9] I was able to smoothly transition to nonparametric statistics, an area that I focused on for a decade; see, e.g., [10, 11].

I still enjoy nonparametric statistics and use this way of thinking whenever possible. However, in the late 1980s, the field was almost entirely focused on iid (identically and independently distributed) data, a foundational sampling scheme that we rarely saw in business. So, I wound up doing research on nonparametric statistics at night, and my day job was focused on teaching regression-based techniques.

Eventually, I was able to combine my day and night jobs by moving my statistical research focus to longitudinal and panel data. This was an area that was of interest to the business community, and so I was able to offer doctoral classes on it and eventually organize my thoughts into a book [12]. Just as important, there is a strong link between longitudinal/panel data and classical insurance credibility theory that I was not aware of when I began this adventure. And this starts my connection with dependence modeling.

\section{How did you learn about copulas?}

I was introduced to copulas by working with Jacques Carrière. My then doctoral student, Emil Valdez, and I had submitted a proposal to the Society of Actuaries in 1994 to study joint-life mortality. We had what we thought was a nice clean model, using an engineering common-shock formulation, that gave readily interpretable expressions for annuity values. We had known Jacques from his days as a doctoral student at UW; he graduated from our Business-Statistics doctoral program. Jacques had been doing work using copulas prior to this time and also had submitted a proposal to the Society of Actuaries. After a little bit of negotiation, we decided to join forces. We calibrated both the common shock and the copula models to the data and the copula turned out to be a clear winner [15]. I thus became a convert to fitting copulas to dependent data and I suppose that I still am. Figure 1 is a group photo of me with others interested in copulas.

At this time, the Society of Actuaries' flagship journal, the North American Actuarial Journal, was just getting started. Along with several others, the editor Sam Cox asked me to write an expository article for the first issue of the journal. I was delighted that Emil Valdez decided to join me in this effort. Emil was still a doctoral student then and so his incentives were clear! We took our assignment seriously; so serious that, in fact, we missed being in the first issue of the journal. Nonetheless, from the continuing citations it seems like our introductory article on copulas [21], on which you and your colleagues provided discussion, Christian [26], has withstood the test of time.

Your paper actually played a determining role in the spread of copula modeling in actuarial science, as documented in [25].

Thanks. Of course, the paper by Embrechts et al. on properties and pitfall of correlation and dependence in risk management, circulated at roughly the same time and later published in a book $[6,7]$ also had a major influence.

\section{Three types of insurance applications}

\section{So, let us focus on dependence modeling. What connections do you see between dependence model- ing and insurance?}

As background, let us first remind ourselves that, at a fundamental level, dependence is a key concept underpinning insurance. Conceptually, an insurance company writes a contract in which it agrees to take on the uncertain risk of a consumer in exchange for a certain price/premium, and an insurance company is nothing more than a collection of such contracts. An insurer exists to spread the risks of many policyholders; insurance systems that can include many insurers are predicated on the pooling of contracts.

Insurers pool risks in order to enjoy the benefits of diversification. But those benefits depend upon the dependence among risks. Some risks are negatively associated and so provide a natural hedge for one another, thus providing diversification benefits. To illustrate, think of the mortality risk in life insurance and annuities. If a policyholder lives longer than anticipated, then in life insurance, benefit payments are further in the future and so are lower in terms of the present value of today's money. In contrast, for a life annuity, the insurer pays while the policyholder is alive. A longer lifespan means more payments. In sum, insurers pay 


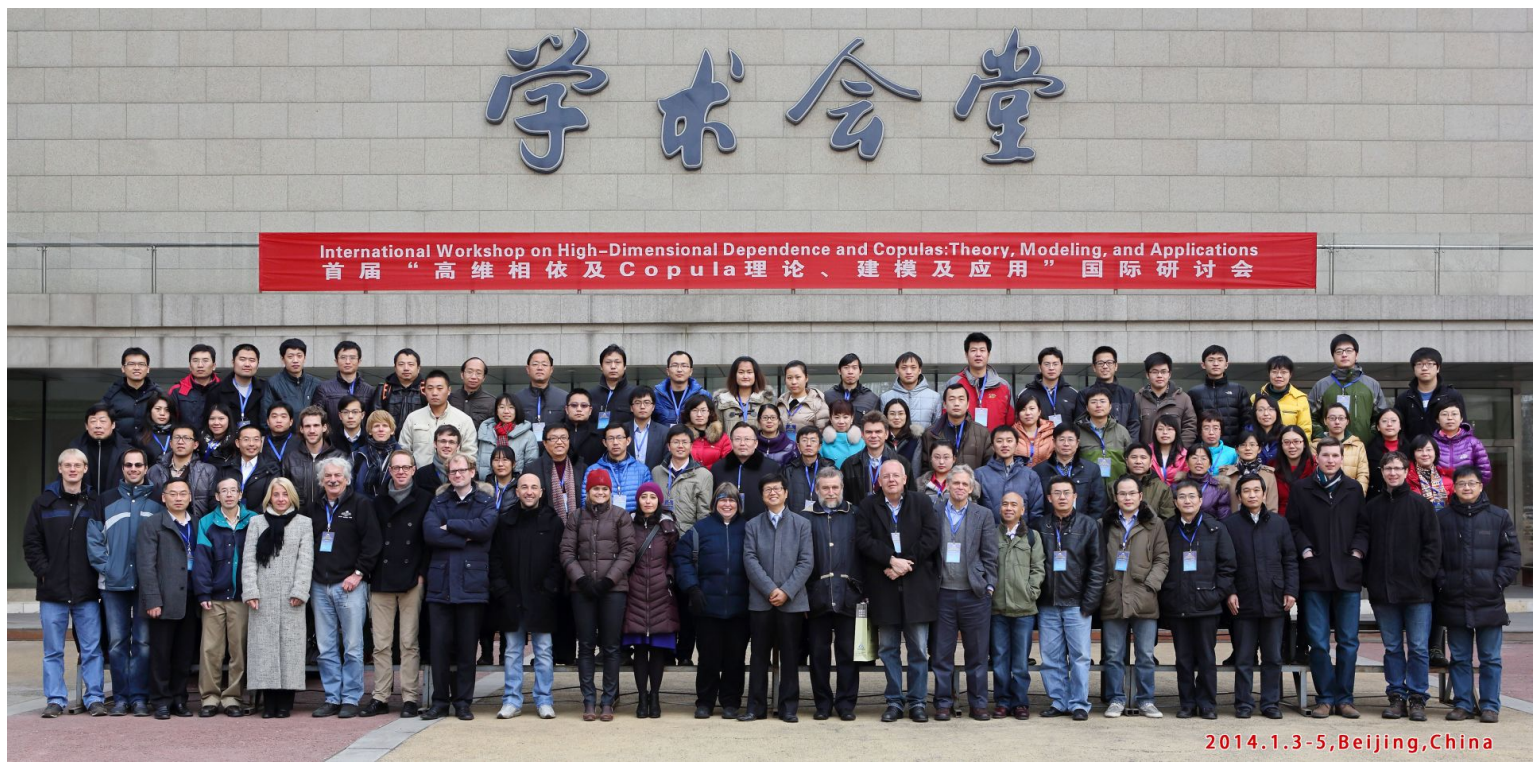

Figure 1: 2014 International Workshop on High-Dimensional Dependence and Copulas: Theory, Modeling, and Applications. Hosted by the China Institute for Actuarial Science at the Central University of Finance and Economics in Beijing. Although you will need to enlarge the picture, many notable dependence modelers are depicted here in the first row, including Harry Joe, Dorota Kurowicka, Roger Cooke, Kjersti Aas, Claudia Czado, and many more.

less in life insurance yet more in annuities, a natural negative association. In contrast, it is more common that insurance risks are positively associated with one another, such as the risk of flood to homes that are located close to one another. There may be few diversification benefits to pooling of such positively associated risks.

Many readers will be intrigued by the title; what types of insurance applications do you have in mind?

I see major impacts of dependence modeling in three areas: (i) actuarial "credibility theory" for pricing of insurance, (ii) dependencies among portfolios for solvency purposes, and (iii) dependencies among claims and contracts for general insurance modeling.

Chronologically, credibility theory takes precedence. This field has a long history and many important questions have been resolved although important specific questions regarding practice continue to surface. Next in time order is dependency modeling for solvency purposes. I think of this as our efforts at "macromodels;" this has been an area of active investigation in the last two decades. Third in line is dependency modeling at the claims and contract level that I regard as "micro-modeling." To me, this is an area ripe with many unsolved questions and a direction that I encourage young researchers to focus upon. Figure 2 shows me trying to convince young researchers of the value of studying dependency modeling in insurance.

\subsection{Credibility theory and longitudinal/panel data}

\section{Can you give a little more background on what you mean by "credibility theory?"}

Credibility theory provides a way of augmenting information from a risk class with related risk classes, prior information, or external collateral information. Dating back at least to papers in 1914 by Albert Mowbray [29] and in 1918 by Albert Whitney [32], credibility has enjoyed a long history in insurance. Credibility has been called a "cornerstone" of actuarial science; see [28]. Originally developed for pricing workers' compensation, credibility has since found applications in other lines of general as well as health insurance. As seen in the Mowbray and Whitney papers, credibility helps to address three important problems: 


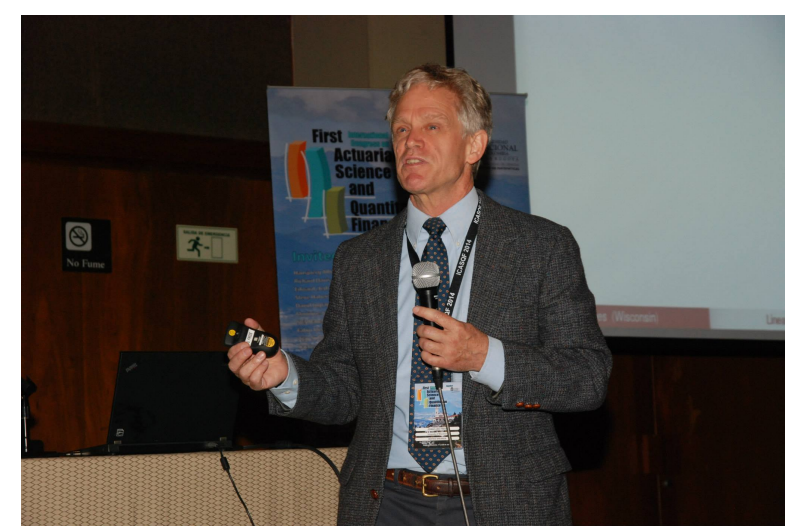

Figure 2: Jed enjoys presenting his work. This is at the First International Congress on Actuarial Science and Quantitative Finance, 2014, Bogotá, Colombia.

1) Sharing of information among risk classes. It is common for a distinct risk class to lack information or exposure upon which the insurer can adequately base prices. When developing a rate for a specific risk class, it is naturally desirable to use information from related risk classes.

2) Experience rating. In this case, the information from a "related risk class" is simply the experience from the risk class in prior periods.

3) Infusing collateral information into rates. At times, an insurer may not have sufficient information from a specific risk class nor from related risk classes and so wishes to incorporate external ("collateral") information.

Credibility is appealing because it is intuitively plausible and helps address important business problems. Because credibility addresses a commercially important problem, there has also been a desire to understand the mathematical underpinnings of credibility estimators. A natural tool for incorporating collateral information in a disciplined manner is through the use of Bayesian methods. In 1950, Arthur Bailey $[1,2]$ introduced the Bayesian model into credibility theory and showed the equivalence between the Bayesian predictive mean and traditional credibility pricing formulas in specific cases.

Another line of research was founded by Hans Bühlmann [3] who postulated an unobserved "structure" variable that is common to several risk classes. This common variable induces a dependency among risk classes, meaning that information from one risk class can be used to draw inferences about other risk classes. In particular, one can develop a credibility rate structure that shares information among risk classes. This framework is popular because resulting credibility estimators are linear in the observations and do not require distributional assumptions about the structural variable (sometimes said to be "distribution-free").

In this set-up, we have

$$
\text { New Premium }=Z \times \text { Claims Experience }+(1-Z) \times \text { Old Premium. }
$$

Here, $Z$ is known as the "credibility factor," with values generally lying between 0 and 1 . The case $Z=1$ is known as "full credibility" where claims experience is used solely to determine the premium. The case $Z=0$ can be thought of as "no credibility," where claims experience is ignored and external information is used as the sole basis for pricing. The book by Bühlmann and Gisler [4] provides an excellent introduction to credibility theory.

\section{What of your involvement with credibility theory?}

This field was relatively mature by the time I started to look at it; for this and other reasons, my contributions were relatively minor. I became interested when I noticed the connections with longitudinal and panel data modeling, an area that I had been studying outside of insurance. In particular, co-authors and I documented that the linear credibility estimators are equivalent to those obtained under the statistical theory of best linear unbiased prediction [24]. We discovered later that this relationship was largely understood from 
the earlier work of Ragnar Norberg [30] but it did get me started in this area. That credibility theory had been developed in a parallel literature is comforting to actuaries (they are on the right track) but also suggests that applications of credibility theory are broader than simply the risk and insurance domain. I reinforced this theme of broad applicability in a chapter in my 2004 book on panel and longitudinal data [12].

I subsequently investigated the link between credibility theory and copulas in papers with Ping Wang $[22,23]$. This investigation helped me understand a point that I believe is under-appreciated to this day; latent variables, such as in credibility theory and longitudinal and panel data, allow analysts to model dependencies in simple and intuitive ways. Specifically, they often provide an intuitively plausible mechanism that analysts can use to explain the results of their work. The copula mechanism provides an alternative framework; it is more flexible and generally easier to calibrate to data structures. It does, however, have the drawback of being less intuitively appealing than alternatives such as latent variables.

\subsection{Modeling insurance at the portfolio or macro level}

\section{How does dependency modeling help insurers model solvency?}

The second area is dependency modeling for solvency purposes and other general risk-management applications that examines large portfolios of insurers at the "macro" level. This is very important for the business of insurance as witnessed by its existence in, for example, European solvency regulations. I have done little in this area and so will not comment on it further except to underscore the importance of this field. Fortunately, this journal (Dependence Modeling) did its first interview with one of the leaders in this field, Paul Embrechts [5]; interested readers can get background from this source.

\subsection{Modeling insurance at the micro level}

For this third area, can you explain more about the connections between dependency modeling and "micro" models of insurance?

Gladly. When working at a granular level, even for claims or policyholders, insurance data are complicated. Results using the classical statistical framework of iid complete data are rarely confronted, at least in insurance applications. Insurance data typically has lots of explanatory variables and, in the big data era, there are some applications where you can underscore the descriptor "lots." It is common to handle this aspect using regression techniques. Moreover, for claims data, it is common to work with distributions that are typically skewed and heavy-tailed; the normal distribution does not even serve as a good starting place. In addition, it is common to encounter situations where there are non-continuous discrete mass points in the distribution.

For example, we often (i) use two-part models to represent the event of loss or no loss, (ii) have losses censored (from the right) by policy limits, and (iii) have losses truncated (from the left) by deductibles. Taken together, these features are complex but by now routine for people working with insurance data. Historically, the field had developed specialized techniques to handle these quirks but now uses standard statistical methods. For readers wishing for more context as to how insurance data arises, one place to start is a review article [14] that I wrote for financial engineers.

In addition to these complex features are dependencies and there may be several sources of dependencies when examining insurance data at the policyholder or claims levels. Even in something as simple as auto insurance, one typically has three types of coverages (for damage to your vehicle, your person, and to another party), each of which are tracked separately but yet can depend upon one another. Also in auto insurance, it is common to have several people insured under a single policy, each of whom brings a separate, but related, risk to the insurance contract.

A person often has several policies with an insurance (one for auto, one for home) and these can be related (e.g., a person careful driving their vehicle is like to be carefully managing the risk to his or her home). Insurers that have many such contracts are worried about spatial dependencies, e.g., have a concentration of policies 
in flood plains, earthquake zones, or hurricane-prone areas. At the commercial level, where the purchaser of insurance is a business, one can easily envision dependencies among different buildings, factories, and so forth, for a business that has a central risk management team. And, for all lines of business, we have temporal dependencies. For example, actuaries, through their study of credibility modeling, have long known that this year's claim level is an excellent predictor of next year's claim level.

As a general approach for modeling dependencies in insurance data, I advocate the use of a copula. I do this because this tool allows us to preserve the work done that represents the complex marginal features. Further, copulas are flexible enough to account for a complex array of dependencies. This has been a relatively recent change in positions for me. For many years, I was concerned about issues of discreteness in copulas, in part due to your influential article with your wife, Christian [27]. However, I think we now have a better understanding about the technical point on the non-uniqueness of copulas in the presence of discreteness; cf. [33].

\section{And what do you see as the future of dependency modeling in "micro" models of insurance?}

There are many open questions on this topic. First, because we are working at a granular or micro-level, there will be many different types of data structures that we are only now addressing, each with its own unique features. As insurers are becoming more aware of the treasure trove of information that their data represents, they become more willing to engage experts to help them extract useful information from their data. I see this as the "how" part.

Just as important, and my biggest challenge, is the "why" part. By this, I am not thinking of determining underlying structural mechanisms such as one does in causal inference. Rather, for insurance, the modeling exercise should be connected to some business goal in order for practitioners to get excited, and wish to invest, in the modeling. An insurance manager wants to know why they should care about dependence modeling. For the macro modeling discussed earlier, there is a clear business purpose; this is understanding the financial stability, or risks of insolvency, of the insurance business. Motivations for dependency modeling at the micro level are less clear. More broadly, insurers use statistical modeling for many business purposes including pricing, underwriting, liability valuation, claims analysis, and so on. For academics who work at the intersection of insurance and statistics, an important area of future research is to develop tools and motivations so that insurers clearly understand the value of dependency modeling. Insurance managers understand that diversification is at the foundation of the insurance business; we simply need to provide clearer arguments on the importance of this field and to provide tools to help them calibrate the impact of dependence on their business.

\section{What about machine learning applications in actuarial science?}

Naturally, actuaries and other participants in the insurance industry are interested in applying machine learning techniques; this is an active research and applications area now. Most of the focus to date has been on pricing and underwriting. However, novel applications have been put forward in micro-level reserving, claims analytics, and other application areas. With respect to dependence modeling, applications and interest are less clear. I imagine, with a cleaner idea of the "why" part of insurance dependence modeling described earlier, we will be better able to speculate on the impact of machine learning on insurance dependence modeling.

\section{Teaching and service}

\section{We would like to get a broader picture of you as an academic and so let us change topics. What type of teaching have you most enjoyed?}

I have had opportunities to teach at all levels during my stint at UW including undergraduate, Master's, and doctoral courses, some for majors and for non-majors (open to all disciplines). I think it is fair to say that I enjoy all levels of teaching. The major courses are nice because you see people in the same profession as you - it gets a little strange when you have a student and then, a couple decades later, you are teaching their children (strange but true). Naturally, I think most faculty have a special affinity for their doctoral students. 


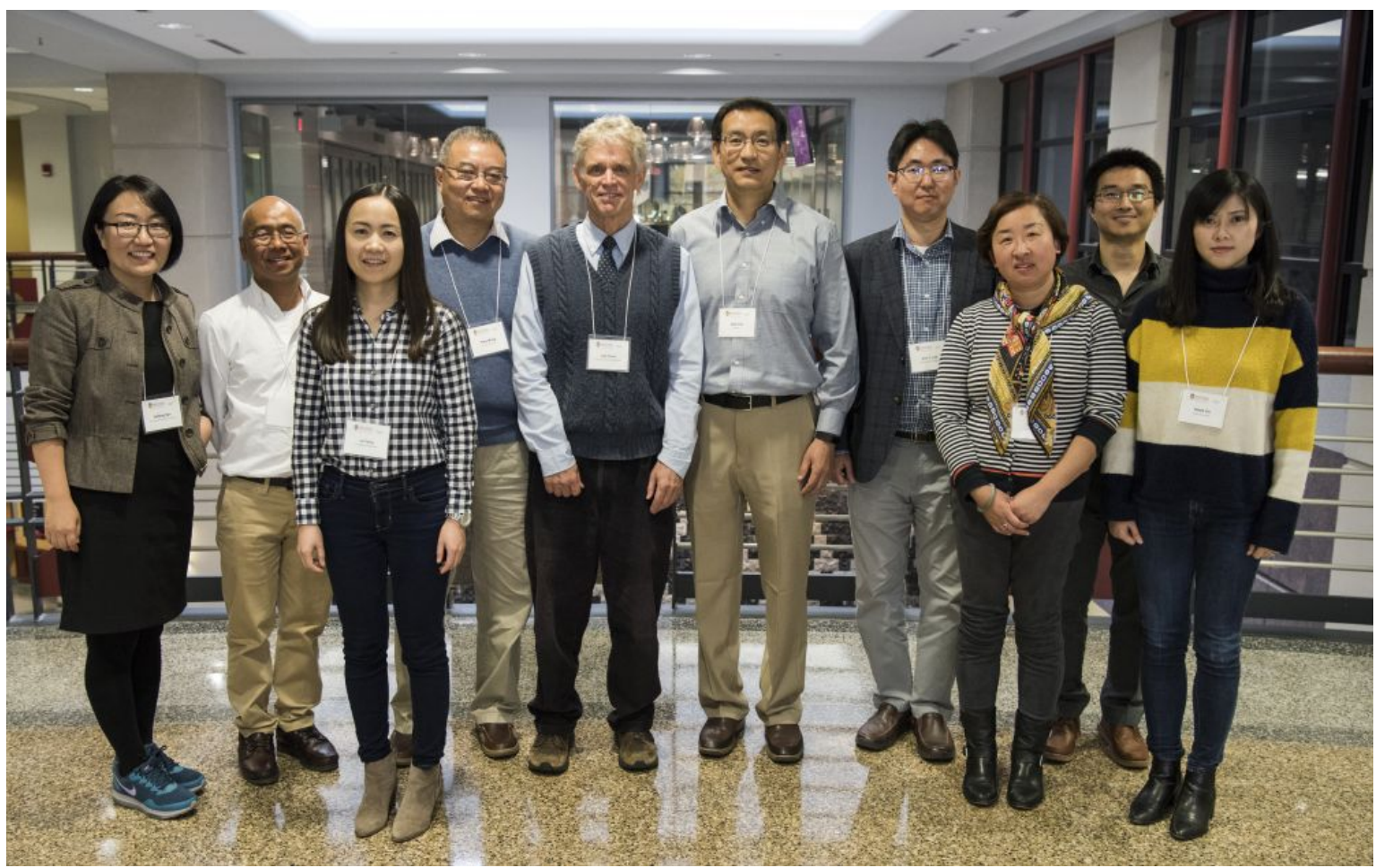

Figure 3: 2018 Frees Retirement Workshop. Pictured with Jed are many of his former doctoral students. From left to right, Jiafeng Sun, Emiliano Valdez, Lu Yang, Ping Wang, Jed, Yu (Jack) Luo, Gee Lee, Jie Gao, Peng Shi, Xiaoli Jin.

This is probably because we spend so much time together during the thesis years which, for the doctoral candidate, is at a critical juncture in their career. It is just a wonderful bonding experience. Figure 3 shows me with some of my former doctoral students. I have truly enjoyed working with each and every one of them. Now that I am at a later stage of my career, I value new PhDs even more; they are the lifeblood of the future of our work.

\section{It sounds like you enjoy teaching. Do you still do so after having retired from UW?}

I do enjoy teaching. However, my usual assignment at UW was to do courses lasting over 14 or 15 weeks; a necessity that is a bit longer than I want now. And, of course, there is the student assessment component (that no faculty really enjoys). In contrast, I still very much enjoy teaching short courses. These give me an opportunity to make a potentially high impact on learners in a relatively short space of time. When coupled with an online learning component (which I employ), it provides an opportunity to make a real difference for a student. I might be there for only 3 days or 3 weeks but, through online components, I can leave behind resources that give students the option to develop skills in remarkable ways. Figure 4 shows me with a class that I taught in August of 2019 through the "Actuaries Without Borders" group. Figure 5 shows me with a class of actuarial teachers in Indonesia. 


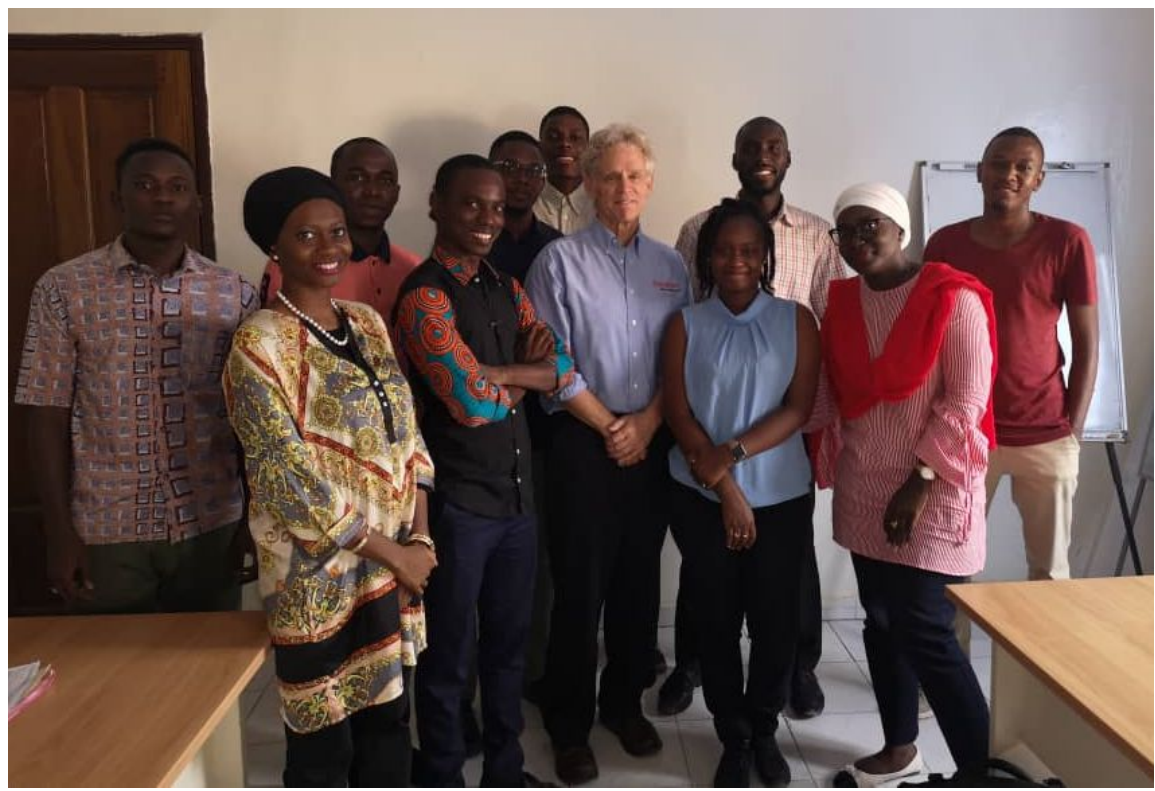

Figure 4: Teaching a short course at IFAGE (Institut interafricain de formation en assurance et en gestion des entreprises), 2019, in Dakar, Senegal. Pictured with Jed are students and fellow faculty, Rokhya Fati (second from left) and Rokhya Kandji (second from right).

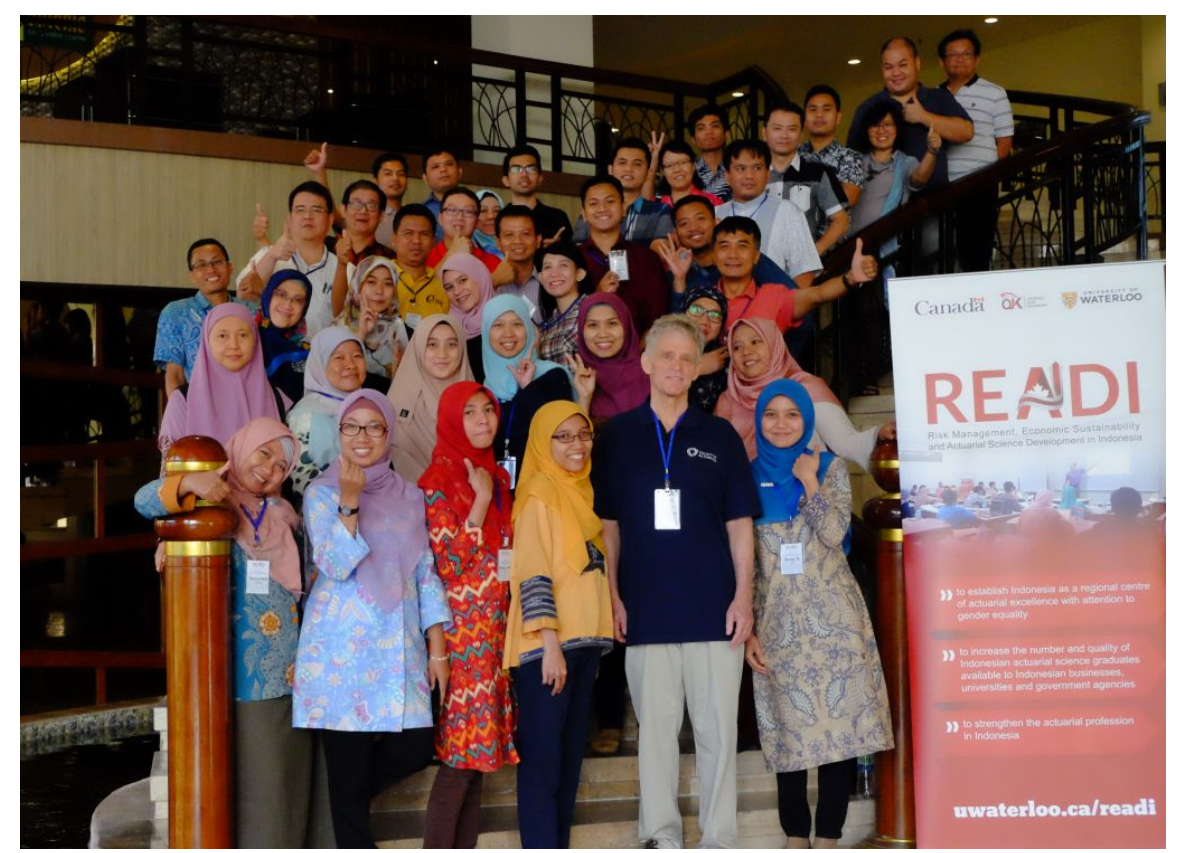

Figure 5: Teaching a short course at READI (Risk Management, Economic Sustainability and Actuarial Science Development in Indonesia), 2018, in Belitung, Indonesia. Pictured here are Jed with short course students who are actuarial faculty in Indonesia.

\section{What do you enjoy most about teaching?}

This may sound strange for an actuary/statistician (definitely not an artist) but it is the creativity I enjoy the most in research and teaching. Most that do research using mathematical tools understand that, by exploring new problems, you need to think a bit differently than others before you, i.e., look for unusual con- 
nections, search for new relationships. By definition, research involves things previously unknown and it is exciting to explore new vistas.

I can make the same case for my teaching. About a decade or so ago, I started to experiment with online learning. After having 25 or so years of traditional teaching under my belt, this gave me a whole new way to look at things. Before this time, I made teaching more interesting by writing textbooks. The online aspects opened up a world of thinking about ways that we can communicate ideas to our constituencies. In the last four years, I have been leading a group that has put together an open, free, interactive textbook that provides core training on one of the foundations of actuarial science. We call the book Loss Data Analytics; please check it out at the URL https://openacttexts.github.io/.

From your CV, it appears that you have placed a considerable emphasis on service activities. Can you describe your approach to service as an academic?

At most universities with a research orientation, service is virtually a negligible component as one works their way through the probationary period; research and teaching are keys to success. However, over the course of an academic career, service to an institution, to the profession, and to the public take on greater roles. And this is exactly how it should be. By providing service, academics influence the direction of an institution, the development of the profession, and the public perception. Without the service component, our voices do not get heard, and society loses.

For my own approach, I sought to be a valuable member of the team. At UW, I had the great fortune to have many terrific colleagues including Bob Miller, Joan Schmit, Margie Rosenberg, Peng Shi, and Jee-Seon Kim. Over the decades, I participated in just about every committee that the UW Business School has including many in leadership roles; I served as department chair twice and once as Associate Dean for Research and Doctoral Programs. My approach to service has been to do 110\%; a little bit more than expected but not so much that people expect you to give up research and teaching.

\section{What about your professional service roles?}

I chose to devote most of my professional service to the actuarial, not the statistics, profession. In part I did this because I felt I could make a greater impact and be more valuable by spending my time giving actuaries an academic viewpoint. Moreover, in service, as with all of our activities, we can learn. By working with professional actuaries, I had opportunities to learn about problems facing them. Research in business is not really all that important unless it is valued by people doing business. The small, but notable, caveat to this statement is that the value may not be realized today but will be in the future.

\section{And what about service to the profession through conference participation?}

I have come to appreciate the value of informal and serendipitous interactions, sometimes working with a colleague whose office is down the hall and sometimes at conferences. Personally, I do not find large meetings with thousands of attendees intellectually stimulating. I most enjoy meetings that are single session with
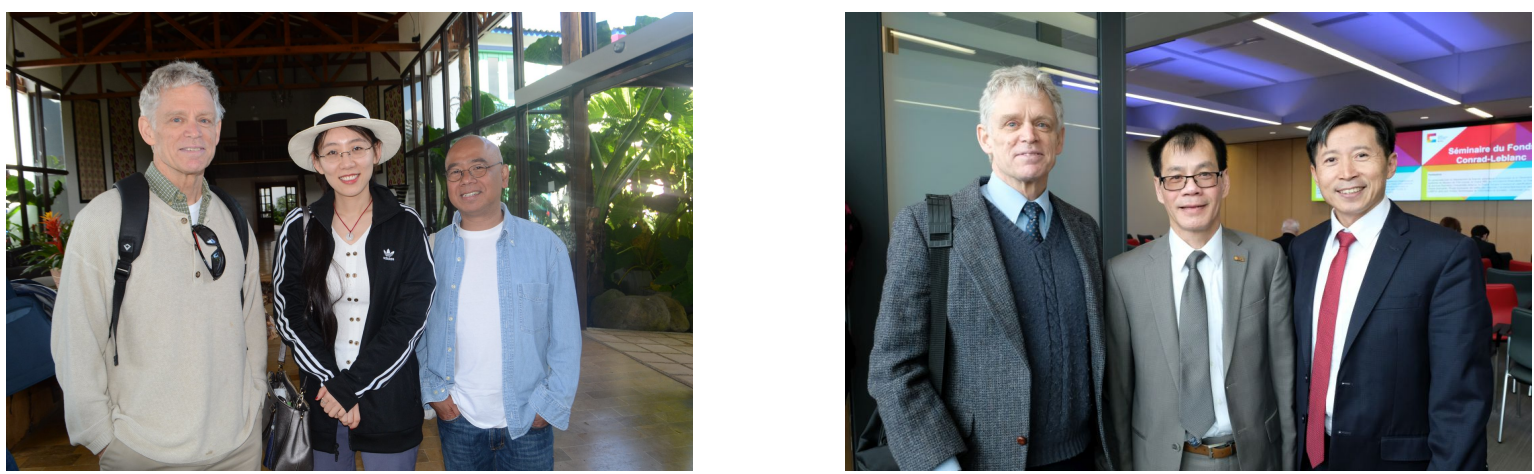

Figure 6: The left-hand picture is Jed with young (relative to Jed) researcher Fangda Liu and his long-time collaborator, Emiliano Valdez. They are participating in the Third International Congress on Actuarial Science and Quantitative Finance, 2019, Manizales, Colombia. The right-hand picture is Jed with host Van Son Lai and Shaun Wang at the Séminaire 2018 du Fonds Conrad-Leblanc held at Université Laval in Québec, Canada. 

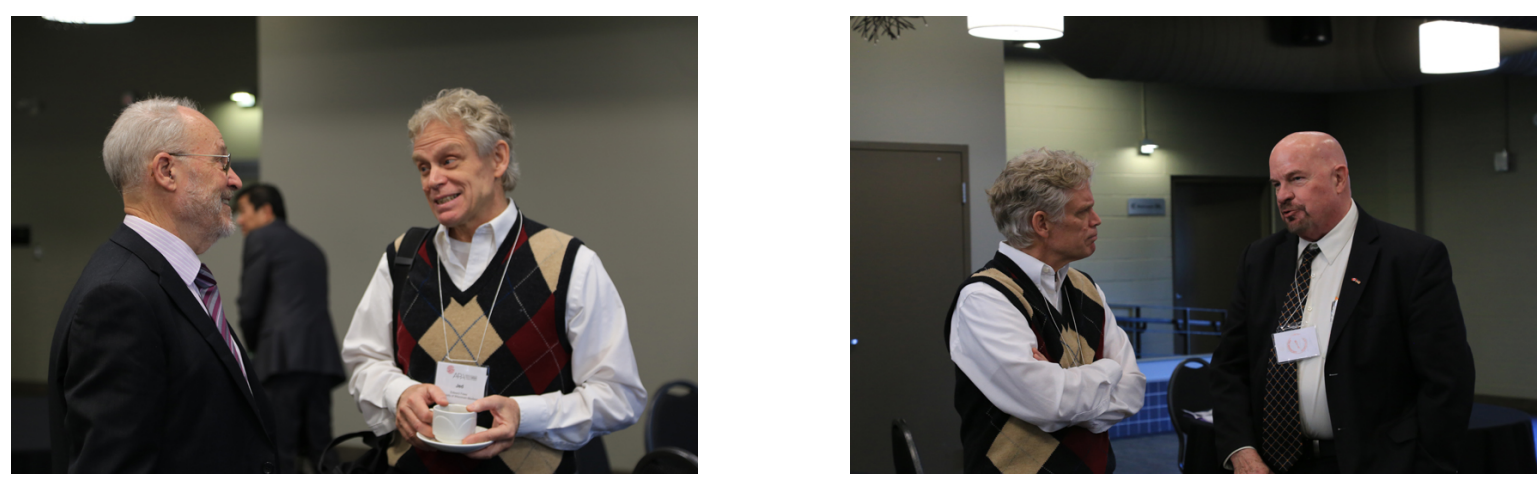

Figure 7: Advances in Predictive Analytics, 2017, University of Waterloo. The left-hand photo is a picture of an animated discussion with Greg Taylor and the right-hand panel shows a more serious discussion with Pat Brockett, two well-known scholars in actuarial science.

only 60-100 people in attendance. You get to meet people who have different backgrounds that are studying different problems. Figures 6 and 7 show me interacting with colleagues at different conferences. I was enjoying myself.

Let us return to the theme of the intersection between statistics and actuarial science. Do you have any thoughts on whether an up-and-coming researcher should work at this intersection?

Actuarial science is an interdisciplinary field with roots in demography, economics, financial economics, mathematics, probability, and statistics. I encourage young researchers to think about paying attention to what is known as a "mother" discipline and think about themselves as a researcher in actuarial science with roots in a foundational field. For me, that field is statistics. Because of the data involved and the probabilistic nature of the contracts (called 'aleatory' in legal jargon) this has always seemed a natural choice. Given the increased emphasis that businesses are paying attention to the so-called "Big Data" movement, the relationship is only going to become stronger. The role of statistics, as a discipline, is to help us interpret data in the context of fields of applications. Insurance, and actuarial science, is one such application area and fits naturally under the broad statistics umbrella.

How should up-and-coming researchers working at this intersection seek research projects?

This is a great question. In response, I will say what works for me. However, it is important that any researcher play to her or his own strengths. There are many good ways to develop research approaches; mine is just one.

For researchers starting to work in actuarial science, here are a couple of tactics I recommend avoiding. One, do not spend an excessive amount of time with mathematical approaches to research such as generalizing someone else's results. I see an inordinate amount of effort, with relatively little value to society, done on this front. Two, especially in the early stages of ones familiarity with a practice field, there is a temptation for researchers to "build a better mousetrap," a new invention that no one has thought of before. Of course, there are some stunning counter-examples, successful inventions built by academics. One is Harry Markowitz's portfolio frontier that revolutionized the way that we think about managing investment portfolios. Another one is the option pricing formula associated with David Li; this has been documented in this journal's interview [31]. But, all too often, academic researchers spend their energy developing approaches to help practicing actuaries better do their jobs; this approach is difficult to accomplish without detailed insight into industry practice.

A better recipe is to simply document what analysts in industry are doing. This may sound a bit naive, so let me explain by example. A former academic who had been working in industry for quite some time, Glenn Meyers, was able to hire me on a fractional basis to work with his firm on problems of interest to them. One of the intriguing problems that they had was that they were using a statistic for model validation that made sense to them but, when presenting it to clients, they could not really explain why it worked and under what conditions it might not work. After three papers that appeared in respected academic outlets in [16- 
18], we were able to say with some reasonable amount of clarity how our insurance Gini statistic worked. The contribution of these papers was not the invention of the statistic. Rather, the papers document how the statistic behaved in general situations so that industry analysts could employ it with comfort.

The lesson of the story is that industry practitioners are typically very knowledgeable about their field. But they lack the time to document their knowledge; to a certain extent, there is a need to keep trade secrets but as a profession there is a good deal of willingness to share ideas as is evidenced by excellent presentations at (actuarial) conferences. They place less value on the notions of building a science and moving the profession forward; these concepts are needed so that analysts throughout the globe can develop and manage risk management systems. And this is where academics can be helpful because this is what we do.

\section{Going forward}

\section{How have you managed to balance your work and outside-of-work activities?}

I feel fortunate to have found a field that suits me so well. I have only been able to enjoy my work as much as I do because I have a solid and supportive family. Our leader is my wife of thirty-plus years, Deirdre; see Figure 8 (right panel). She and I have built a great life together with our two sons, Adam and Nathan, as well as the newer member of our family, Adam's wife Claire. We only have grand-dogs at this point, Mari and Newton, but there is still hope for new arrivals. We see each other regularly, especially at holidays, have common interests (Deirdre and Claire both teach elementary school) and actually get along. A real joy.

\section{Besides family time, what are you interested in outside of work?}

I enjoy physical activity and reading science fiction/fantasy. For me, physical activity has changed over the decades and has included (American) football, track, ballet and modern dance, squash, racquetball, karate, kung fu, and most recently, tai chi, bicycling, and swimming. Figure 8 (left panel) shows me a long time ago in an ad for a ballet performance. In contrast, reading science fiction/fantasy has always been there.

You seem enthusiastic about all parts of academia and yet retired in 2018 . What does the future hold?

I think it safe to say that I have more years behind me than I do in front of me. I enjoyed my 35 years at the University of Wisconsin-Madison tremendously and still do think it is one of the best jobs in the world. However, after 35 years, I was ready for new adventures. I am delighted to have a fractional appointment with the Australian National University now. This position allows me to focus on research and to mentor junior faculty and doctoral students, areas where I think I can be most helpful. Except for the bushfires that Australia has experienced recently (in early 2020), Canberra is a lovely city and an easy place to be. As the country's capital, it has many terrific cultural opportunities.

For the research projects themselves, I am now trying to take on riskier projects, working in areas outside of my comfort zone. In part this is to challenge myself but also because I hope to be able to contribute in some meaningful ways. It has been said that one can think of retirement years as a "long-term sabbatical." This has certainly been my approach. I love to learn.

\section{Thanks again for letting us interview you and our very best for the coming years!}

Acknowledgments and credits The figure with Van Son Lai and Shaun Wang was retrieved from https: //www.flickr.com/photos/fsaulaval/40788136934/in/album-72157667873343428/. The photos from the Waterloo Conference are from https://uwaterloo.ca/advances-in-predictive-analytics/apa-conference-photos. The photos from the two International Congress on Actuarial Science and Quantitative Finance from https: //www.facebook.com/pg/ICASQF/photos/. The 2014 group photo was provided by conference organizer Professor Ken Seng Tan <kensengtan@gmail.com>, <kenseng.tan@ntu.edu.sg>. The photos from READI are also via Professor Ken Seng Tan. Photos of Jed and his retirement are from the Wisconsin School of Business. All other photographs are from his personal collection. 

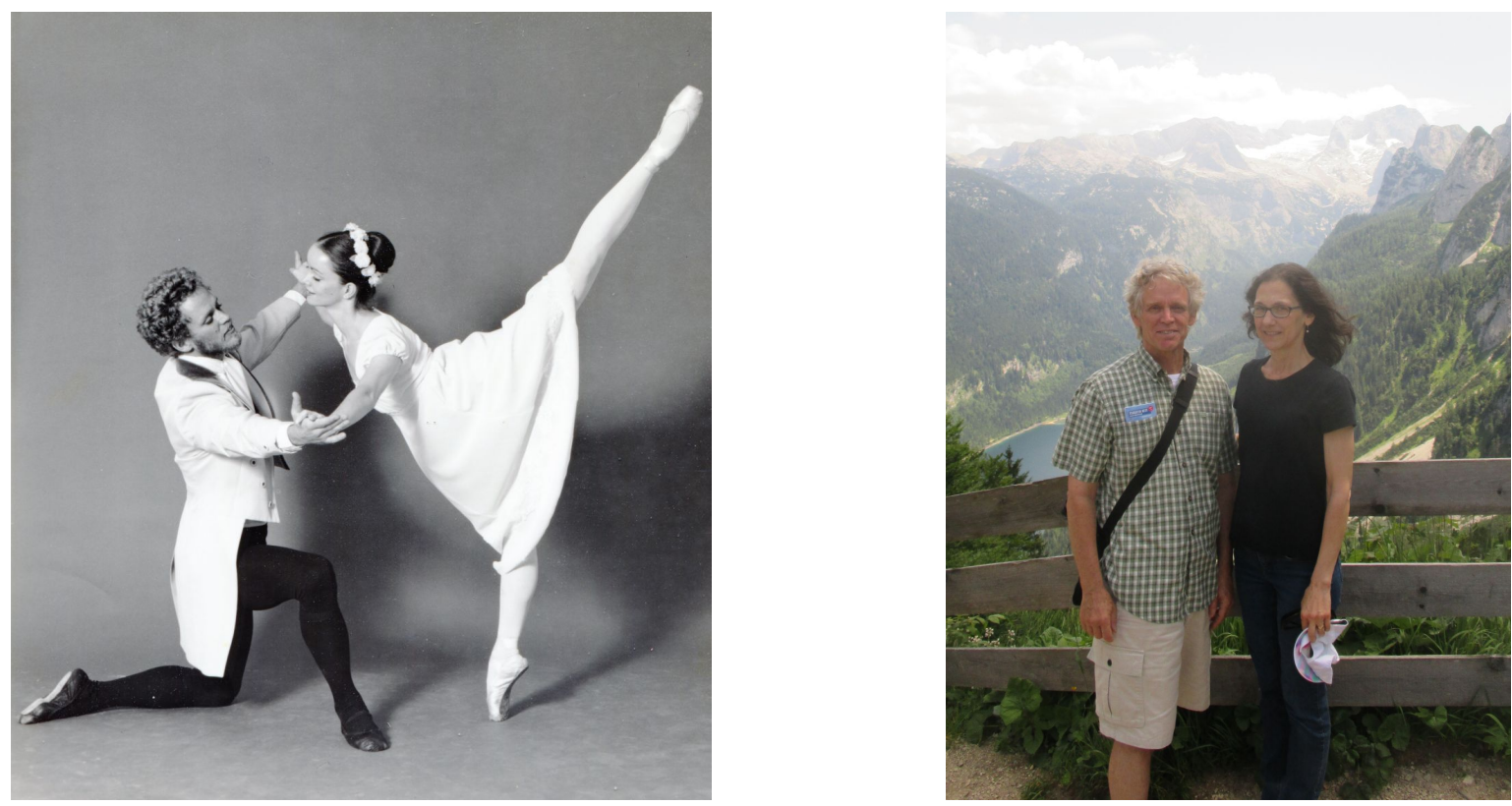

Figure 8: The left-hand photo shows Jed with M'Liss (Gary) Dorrance from a ballet performance while he was a doctoral student in 1982. The right-hand photo is Jed and Deirdre in the Austrian Alps after the 2017 Insurance Mathematics Conference in Vienna.

\section{References}

[1] Bailey, A.L. (1950). Credibility procedures, Laplace's generalization of Bayes' rule and the combination of collateral knowledge with observed data. Proceedings of the Casualty Actuarial Society 37(67), pp. 7-23.

[2] Bailey, A.L. (1950). Credibility procedures, Laplace's generalization of Bayes' rule and the combination of collateral knowledge with observed data: Discussion. Proceedings of the Casualty Actuarial Society 37(68), pp. 94-115.

[3] Bühlmann, H. (1967). Experience rating and credibility. Astin Bull. 4(3), 199-207.

[4] Bühlmann, H. and A. Gisler (2005). A Course in Credibility Theory and its Applications. Springer, Berlin.

[5] Durante, F., G. Puccetti, and M. Scherer (2015). Building bridges between mathematics, insurance and finance: An interview with Paul Embrechts. Depend. Model. 3, 17-28.

[6] Embrechts, P., A.J. McNeil, and D. Straumann (1999). Correlation: Pitfalls and alternatives. RISK 12(5), 69-71.

[7] Embrechts, P., A.J. McNeil, and D. Straumann (2002). Correlation and dependence in risk management: Properties and pitfalls. In M. Dempster (Ed.), Risk Management: Value at Risk and Beyond, pp. 176-223. Cambridge University Press.

[8] Frees, E.W. (1983). On Construction of Sequential Age Replacement Policies via Stochastic Approximation. PhD thesis, The University of North Carolina at Chapel Hill, Chapel Hill NC.

[9] Frees, E.W. (1986). Nonparametric renewal function estimation. Ann. Statist. 14(4), 1366-1378. [Corr: 16(4), 1741.]

[10] Frees, E.W. (1989). Infinite order U-statistics. Scand. J. Statist. 16(1), 29-45.

[11] Frees, E.W. (1994). Estimating densities of functions of observations. J. Amer. Statist. Assoc. 89(426), 517-525.

[12] Frees, E.W. (2004). Longitudinal and Panel Data. Cambridge University Press.

[13] Frees, E.W. (2007). James C. Hickman: An actuary who made a difference. N. Am. Actuar. J. 11(1), 1-11.

[14] Frees, E.W. (2015). Analytics of insurance markets. Ann. Rev. Financ. Econom. 7, 253-277.

[15] Frees, E.W, J. Carrière, and E.A. Valdez (1996). Annuity valuation with dependent mortality. J. Risk Insur. 63(2), $229-261$.

[16] Frees, E.W., G. Meyers, and A.D. Cummings (2011). Summarizing insurance scores using a Gini index. J. Amer. Statist. Assoc. 106(495), 1085-1098.

[17] Frees, E.W., G. Meyers, and A.D. Cummings (2012). Predictive modeling of multi-peril homeowners insurance. Variance 6(1), 11-31.

[18] Frees, E.W., G. Meyers, and A.D. Cummings (2013). Insurance ratemaking and a Gini index. J. Risk Insur. 81(2), 335-366.

[19] Frees, E.W. and D. Ruppert (1985). Sequential nonparametric age replacement policies. Ann. Statist. 13(2), 650-662.

[20] Frees, E.W. and D. Ruppert (1990). Estimation following a sequentially designed experiment. J. Amer. Statist. Assoc. 85(412), 1123-1129.

[21] Frees, E.W. and E.A. Valdez (1998). Understanding relationships using copulas. N. Am. Actuar. J. 2(1), 1-25. 
[22] Frees, E.W. and P. Wang (2005). Credibility using copulas. N. Am. Actuar. J. 9(2), 31-48.

[23] Frees, E.W. and P. Wang (2006). Copula credibility for aggregate loss models. Insurance Math. Econom. 38(2), 360-373.

[24] Frees, E.W., V.R. Young, and Y. Luo (1999). A longitudinal data analysis interpretation of credibility models. Insurance Math. Econom. 24(3), 229-247.

[25] Genest, C., M. Gendron, and M. Bourdeau-Brien (2009). The advent of copulas in finance. Eur. J. Finance 15(7-8), 609-618.

[26] Genest, C., K. Ghoudi, and L.-P. Rivest (1998). Comments on "Understanding relationships using copulas," by Edward Frees and Emiliano Valdez. N. Am. Actuar. J. 2(3), 143-149.

[27] Genest, C. and J. Nešlehová (2007). A primer on copulas for count data. Astin Bull. 37(2), 475-515.

[28] Hickman, J.C. and L. Heacox (1999). Credibility theory: The cornerstone of actuarial science. N. Am. Actuar. J. 3(2), 1-8.

[29] Mowbray, A.H. (1914). How extensive a payroll exposure is necessary to give a dependable pure premium? Proceedings of the Casualty Actuarial Society 1(1), pp. 24-30.

[30] Norberg, R. (1986). Hierarchical credibility: Analysis of a random effect linear model with nested classification. Scand. Act. J. 1986(3-4), 204-222.

[31] Puccetti, G. and M. Scherer (2018). Copulas, credit portfolios, and the broken heart syndrome: An interview with David X. Li. Depend. Model. 6, 114-130.

[32] Whitney, A.W. (1918). The theory of experience rating. Proceedings of the Casualty Actuarial Society 4(10), pp. 274-292.

[33] Yang, L., E.W. Frees, and Z. Zhang (2020). Nonparametric estimation of copula regression models with discrete outcomes. J. Amer. Statist. Assoc., to appear. Available at https://doi.org/10.1080/01621459.2018.1546586. 